\title{
DELINEAMENTO ETIOLÓGICO DA DOENÇA DE ALZHEIMER EM UM GRUPO DE PORTADORES NO MUNICÍPIO DE PONTA GROSSA E REGIÃO
}

\author{
ETIOLOGICAL DESIGN OF ALZHEIMER'S DISEASE IN A GROUP OF CARRIERS IN \\ THE MUNICIPALITY OF PONTA GROSSA AND REGION
}

\author{
Alan Rodrigo Sulareviscz ${ }^{1^{\star}}$, Camila de Fatima Carvalho', Vanessa Cristina Godoy \\ Jasinski
}

\author{
1 - Discente do Curso de Farmácia - Centro de Ensino Superior dos Campos Gerais, Ponta \\ Grossa - Paraná - CESCAGE \\ 2 - Docente do Curso de Farmácia - Centro de Ensino Superior dos Campos Gerais, Ponta \\ Grossa - Paraná - CESCAGE
}

\section{RESUMO:}

O envelhecimento da população brasileira é uma das maiores preocupações de ordem pública, pois nessa faixa etária há maior propensão de desenvolver doenças crônicas, assim como a Doença de Alzheimer (DA). A DA é considerada uma demência, pois trata-se de uma patologia neurogenerativa irreversível, que acomete todas as funções cognitivas naturais e cotidianas do ser humano, sendo essa provocada pela redução da massa neuronal devido a desnaturação da proteína $\beta$-amiloide. Embora existam muitos estudos aplicados a sua origem, desenvolvimento e métodos de prevenção, ainda não foi descoberta a cura. Além disso, notase uma precariedade quanto aos estudos epidemiológicos, os quais poderiam mensurar a distribuição dos fatores etiológicos entre os seus portadores. Baseado nisso, o presente trabalho dedicou-se a investigar quatro dos possíveis fatores desencadeadores da DA, como: a herança genética, os traumas psicoemocionais, Diabetes Mellitus (DM) e a qualidade nutricional. A pesquisa comunitária foi realizada com um total de 32 idosos residentes em Ponta Grossa e região, através de entrevistas com seus cuidadores, sejam eles familiares ou não. Os resultados foram obtidos mediante a determinação da prevalência transversal em um estudo analítico e observacional. A associação entre todas as evidências científicas existentes e as informações obtidas apresentaram significativa relação dos fatores etiológicos, frente ao histórico de vida dos idosos. Entre os resultados, nota-se que cerca de $75 \%$ dos pacientes são mulheres, com idade predominante ente 70 e 79 anos. No que se refere aos fatores etiológicos, a herança genética manifestou-se em $34,4 \%$ dos idosos, $53,2 \%$ foram caracterizados como vítimas de traumas psicoemocionais, $34,4 \%$ foram afetados pela DM e $56,2 \%$ por maus hábitos alimentares. Com isso, o estudo realizado explana um importante respaldo voltado a comunidade local e aos pesquisadores interessados, pois estabeleceu uma relevante hipótese entre a genética e a qualidade de vida, como influenciadores para o desencadeamento da DA. Palavras-chave: TAU. Beta-amiloide. Doença de Alzehimer. Demência. Qualidade de vida.

\section{ABSTRACT:}

The aging of the Brazilian population is one of the greatest concerns of public order, since in this age group there is a greater propensity to develop chronic diseases, as well as Alzheimer's Disease (AD). AD is considered a dementia, as it is an irreversible neurogenerative pathology, which affects all natural and everyday cognitive functions of humans, which is caused by the reduction of neuronal mass due to the denaturation of the $\beta$-amyloid protein. Although there are many studies applied to its origin, development and 
prevention methods, a cure has not yet been discovered. In addition, there is a precariousness regarding epidemiological studies, which could measure the distribution of aetiological factors among their carriers. Based on this, the present work was dedicated to investigating four of the possible triggering factors of $A D$, such as: genetic inheritance, psychoemotional traumas, Diabetes Mellitus (DM) and nutritional quality. The community survey was conducted with a total of 32 elderly people living in Ponta Grossa and region, through interviews with their caregivers, whether they are family members or not. The results were obtained by determining the cross-sectional prevalence in an analytical and observational study. The association between all the existing scientific evidence and the information obtained showed a significant relationship between the etiological factors, in view of the life history of the elderly. Among the results, it is noted that about $75 \%$ of the patients are women, with a predominant age between 70 and 79 years. With regard to etiological factors, genetic inheritance was manifested in $34.4 \%$ of the elderly, $53.2 \%$ were characterized as victims of psycho-emotional trauma, $34.4 \%$ were affected by DM and $56.2 \%$ by bad habits food. Thus, the study carried out explains an important support aimed at the local community and interested researchers, as it established a relevant hypothesis between genetics and quality of life, as influencing the triggering of $A D$.

Keywords: TAU. Beta-amyloid. Alzheimer's disease. Dementia. Life quality.

\section{INTRODUÇÃO}

Uma das preocupações voltadas à saúde pública no Brasil é o aumento do número de idosos entre a população. Nesse contexto explana-se intervenções para melhorar a qualidade dos brasileiros. Sabe-se que pessoas, cuja faixa etária supera os 60 anos, são propensas a desenvolver inúmeras patologias crônicas, entre elas a doença de Alzheimer (DA) (VERAS, 2007; MENDES et al., 2018).

Descoberta por Alois Alzheimer, neuropatologista e psiquiatra, a doença se manifesta de acordo com uma atrofia cortical difusa, deposição de proteínas $\beta$-amiloide (placas senis e emaranhados neurofibrilares) que se agrupam e bloqueiam a sinalização entre as células neuronais durante as sinapses, degeneração vascular, perda de neurônios e massas neurofibrilares da proteína tau. Além dessas alterações estruturais, nota-se alguns achados bioquímicos, como neuroinflamação, deficiência de mitocôndrias, estresse oxidativo, desregulação da concentração de cálcio, glutamato e acetilcolina (FALCO et al., 2016).

Portanto, a DA é classificada como uma demência, pois acomete severamente as funções cognitivas do portador. Seu mecanismo, simplificadamente, resume-se na interrupção da transmissão de neurotransmissores, acompanhada da desnaturação e atrofia, os quais desencadeiam sintomas como a perda da memória, confusão, desorientação, agressividade e dependência, em concordância com o grau evolutivo (MKCHANN et al., 1984; FALCO et al., 2016; FERNANDES; ANDRADE, 2017; BERNARDO, 2018). 
De acordo com os estudos desenvolvidos por Moura, Miranda e Rangel (2015), a DA é submetida a quatro estágios de evolução. No primeiro estágio, o indivíduo apresenta desorientação temporal e espacial. Já em segunda instância, surgem sintomas como agressividade e perda significativa da memória. No terceiro estágio da demência, ocorre o comprometimento verbal e o esquecimento abrasivo. Concluindo a evolução, encontramse o comprometimento motor e constante dependência do seu cuidador.

Etiologicamente a DA ainda é misteriosa, pois as inúmeras pesquisas existentes abordam múltiplos fatores. Entre os quais o histórico de saúde do indivíduo é o principal alvo dessa pesquisa, pois sabe-se que a herança genética, os traumas psicoemocionais, a Diabete Mellitus (DM) e a qualidade nutricional são relevantes, frente a sua ocorrência (MOURA; MIRANDA; RANGEL, 2015; FERNANDES; ANDRADE, 2017).

Entre inúmeros estudos a respeito da DA, as mutações genéticas estão em grande destaque. Consiste em alterações anormais nas sequências de pares químicos que compõem os genes. Em alguns genes parecem explicar completamente a patogenia desse tipo de DA familiar: o gene da proteína precursora amilóide (APP), o gene da présenilina 1 (PSNE1), o gene da présenilina 2 (PSNE2) e os genes da apolipoproteína (Apo) (PAULA et al., 2009; BELCAVELLO, 2014).

Pacientes caracterizados como depressivos mantém elevada dificuldade cognitiva. A redução da massa do hipocampo, frente as características de declínio explanam que a DA pode, em muitos casos, estar relacionada a situação depressora do indivíduo. Traumas frequentes ao longo da vida, em grau extremo de perturbação psicoemocional, acarretam problemas neuronais, bem como interferem no armazenamento de informações (PEREIRA et al, 2016; MIRI et al., 2017).

A DM possui uma fisiopatologia explicada pela carência de insulina para efetuar o controle glicêmico a nível sistêmico. Durante as crises hiperglicêmicas, ocorre a atrofia energética que compromete a cognição, visto que a insulina é responsável pela interiorização da proteína $\beta$-amilóide nos neurônios, sendo o seu acúmulo uma das precursoras no desenvolvimento da DA (LOPES et al., 2018).

Em sequência aos estudos, Thomas et al. (2015), Silva, Alves (2017), Wilde et al. (2017), relatam que a redução de micronutrientes antioxidantes está relacionada com a DA. Essa diminuição tem um efeito negativo no estresse oxidativo de colina, vitamina B12, folato, vitamina C e vitamina $\mathrm{E}$. Um dos mecanismos envolvidos no processo de manifestação da DA consiste na depleção do armazenamento de Vitamina D e Ômega-3.

Portanto, a elaboração da pesquisa, bem como a seleção das informações trazem o intuito de compreender a complexidade da DA. Sobretudo, relacionando todos os fatores citados a um grupo de idosos já diagnosticados. 


\section{MATERIAL E MÉTODOS}

O delineamento geral do estudo analítico e observacional de prevalência transversal, realizado em Ponta Grossa e região está representado na Figura 1. Inicialmente, conduziu-se um censo que identificou idosos residentes nos municípios-alvo, no período de fevereiro a maio de 2020 (BRASIL, 2010).

Após aprovação do desenvolvimento da pesquisa através do Comitê de Ética e Pesquisa (CEP), número 30287320.3.0000.5215, os cuidadores ou responsáveis de idosos portadores da DA foram convidados a participar de uma entrevista, mediante o envio de um formulário, através da ferramenta Google Forms. As informações obtidas abordavam as características sociodemográficas, análise do histórico familiar, informações psicossociais e anamnese nutricional.

Solicitou-se o compromisso com o formulário de pesquisa, mediante uma introdução explicativa e assinatura digital dos entrevistados, como garantia de legitimidade de todas as informações.

Os casos selecionados foram quantificados, sendo excluídos os pacientes que se encontravam em situação abandono ou autocuidado. Totalizou-se, assim, 32 pacientes para o acompanhamento, os quais se enquadraram no critério estabelecido.

Todos os pacientes reportados pelos familiares e cuidadores apresentavam o diagnóstico clínico da doença, mediante análises observacionais e exames médicos, conforme solicitado aos entrevistados.

Figura 1 - Fluxograma do desenvolvimento do estudo.

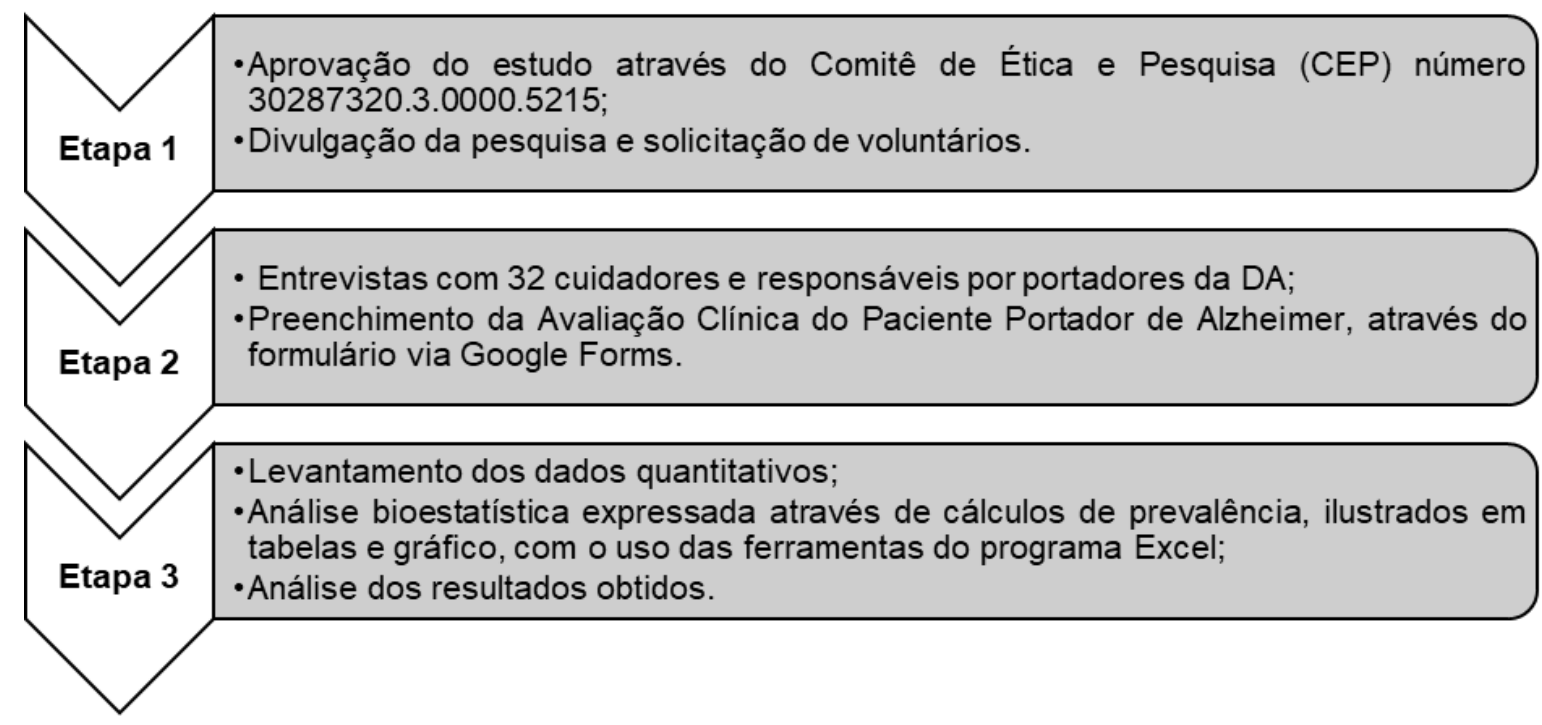

Fonte: $\mathrm{O}$ autor. 
A utilização desse método de entrevista possibilitou avaliar os possíveis impactos de cada fator etiológico no desenvolvimento da doença.

$\mathrm{Na}$ avaliação de casos relacionados a manifestação de ordem genética, foi investigado a existência da DA em familiares do portador, sendo também verificados o grau de parentesco. Foi estabelecida a relação de proximidade, como, pai, mãe, irmãos, tios ou primos.

Em relação aos traumas psicoemocionais foi verificada a existência de possíveis distúrbios psicológicos adquiridos ao longo de sua vida. Neste sentido, caracterizavam-se situações de violência, morte de pessoas próximas, divórcios, entre outros possíveis aspectos que desencadearam sentimentos autodestrutivos, suficientemente capazes de deteriorar a sanidade psicológica e comportamental. Contudo, a intimidade do paciente não foi questionada por respeito a sua privacidade.

O estudo de prevalência de idosos portadores da DM referia-se ao tempo e a relação entre esse distúrbio com o desencadeamento da DA. Neste sentido foi investigado também a manifestação da DM em outros familiares.

Logo, para avaliar o comportamento nutricional de cada idoso ao longo de sua vida, primeiramente foi estabelecida a determinação do parâmetro antropométrico, baseados em peso atual e estatura, dados obtidos através do acompanhamento médico. Tais informações sugerem idosos em estados de sobrepeso, obesidade ou desnutrição, através do cálculo de índice de massa corporal (IMC).

$$
\text { IMC }=\frac{\text { Peso }(\mathrm{Kg})}{\text { Altura }^{2}(\mathrm{~m})}
$$

O IMC é a relação existente entre o peso do indivíduo e a sua altura, elevadas ao quadrado, cuja classificação está ilustrada na tabela 1 (CUPPARI, 2005; EUGÊNIO; CARVALHO, 2016).

Tabela 1 - Classificação do índice de massa corporal (IMC).

\begin{tabular}{ll}
\hline IMC $\left(\mathbf{K g} / \mathbf{m}^{2}\right)$ & CLASSIFICAÇÃO \\
\hline $16,0-18,4$ & Magreza \\
$18,25-24,9$ & Eutrofia \\
$25,0-29,9$ & Sobrepeso \\
$>30,0$ & Obesidade \\
\hline
\end{tabular}

Fonte: CUPPARI, 2005. Adaptado. 
Em concordância a isso, foi investigada a qualidade nutricional, de acordo com o consumo de diversos alimentos, com o intuito de estabelecer uma lógica para a relação entre a DA e a alimentação.

Todas informações obtidas na linha de base deste estudo compõem variáveis exploratórias (fatores etiológicos) e sua associação a DA. A adesão do estudo foi mediana, mostrando que o método de abordagem da comunidade foi adequado e as ferramentas empregadas trouxeram uma condição essencial para uma pesquisa, baseada em estudo de prevalência.

Por se tratar de um estudo transversal, foi avaliada a frequência dos eventos etiológicos em um curto período, a fim de se obter informações concretas, limitando a investigação da associação entre o risco e a doença.

Os dados coletados foram expressos em números para posterior mensuração, ilustrada em tabelas e gráfico de colunas. Foi empregada a Taxa de Prevalência $(P)$ como método matemático para a quantificação dos casos reportados (BRASIL, 2010).

A fórmula estatística selecionada, devido a sua praticidade e especificidade geográfica, garante que os dados obtidos não se desviaram de uma lógica concisa e de fácil interpretação.

$$
P=\frac{n^{\circ} \text { de idosos submetidos ao fator de risco } \times \text { no tempo }}{n^{\circ} \text { de idosos afetados pela DA }} \times 100
$$

Estabeleceu-se, assim, a razão que existe entre os pacientes expostos aos fatores etiológicos, em um determinado grupo de portadores da doença, mediante um período de três meses de acompanhamento (BRASIL, 2010).

\section{RESULTADOS E DISCUSSÕES}

Nos últimos anos, há um crescimento significativo no número de pessoas idosas. Estima-se que, no Brasil, $13 \%$ da população tem idade superior a 60 anos. Com o envelhecimento populacional, o sistema de saúde deverá se readequar para atender a diversas doenças crônicas, entre elas a DA (MOSER, 2010; SOUZA; MARQUETTE, 2018).

Atualmente, pesquisar de forma quantitativa e prevalente é necessário para estabelecer uma linha tênue entre a observação da qualidade de vida da população frente ao desenvolvimento de doenças (VERAS, 2007; THOMAS et al. 2015; SOUZA; MARQUETTE, 2018). 
Neste sentido, o presente estudo foi pioneiro em trazer resultados sobre o impacto da genética, qualidade nutricional, portabilidade de DM e traumas psicoemocionais vivenciados, como possíveis fatores desencadeadores da DA. Com isso, surgiram as seguintes hipóteses: Qual é a relação entre esses fatores etiológicos com a DA? Quais são os impactos gerados na vida do homem? Com que prevalência esses fatores se desenvolvem?

A amostra foi composta por 32 idosos, diagnosticados como portadores da DA. Esses idosos foram numerosamente representados por mulheres, no total de $75 \%$, enquanto apenas $25 \%$ dos idosos são do gênero masculino.

A faixa etária encontra-se com predominância para pessoas entre 70 e 79 anos, assumindo um total de $46,9 \%$. Seguidos de $37,5 \%$ dos idosos, com idade acima de 80 anos. $15,6 \%$ do grupo a idade estava entre 60 e 69 anos.

Desses, $75 \%$ moram com seus familiares e recebem seus cuidados, sendo os demais, $25 \%$, encontrados em casas de acolhimento.

Em relação ao tempo de convívio com a doença, 40,6\% está a mais de 6 anos como diagnosticado e recebendo os cuidados previstos. Outros 40,6\% foi diagnosticado nos últimos 3 anos. E 18,8\% dos casos estão entre o tempo intermediário de diagnóstico e permanência comum de enfrentamento da DA, entre 3 e 6 anos.

Tabela 2 - Características sociodemográficas dos pacientes portadores da DA.

\begin{tabular}{lcccc}
\hline \multirow{2}{*}{ Variáveis } & \multicolumn{2}{c}{ Homens } & \multicolumn{2}{c}{ Mulheres } \\
\cline { 2 - 5 } & Número & $\%$ & Número & $\%$ \\
\hline Gênero & 8 & 25 & 24 & 75 \\
Idade & & & & \\
60 a 69 anos & 2 & 6,25 & 3 & 9,4 \\
70 a 79 anos & 2 & 6,25 & 13 & 40,6 \\
$>80$ anos & 4 & 12,5 & 8 & 25 \\
& & & & \\
Moradia & & & 18 & 56,25 \\
Familiares & 6 & 18,75 & 6 & 18,75 \\
Acolhimento & 2 & 6,25 & & \\
Tempo de diagnóstico & & & & \\
1 a 3 anos & & & & \\
3 a 6 anos & 2 & 6,25 & 11 & 34,4 \\
$>6$ anos & 2 & 6,25 & 4 & 12,5 \\
\hline
\end{tabular}

Fonte: $O$ autor. 
Sabe-se que o tratamento farmacológico contribuir com o retardamento do progresso evolutivo da doença, evitando o comprometimento imediato da maioria das funções cognitivas. Entre os medicamentos utilizados estão os inibidores da acetilcolinesterase (Cloridrato de Donepezila, Hemitartarato de Rivastigmina e Bromidrato de Galantamina), inibidores seletivos e competitivos reversíveis da acetilcolinesterase, ou seja, atuam nos receptores nicotínicos aumentando a ação da acetilcolina sobre o sistema colinérgico para a melhora da função cognitiva do portador da DA (KATZUNG; TREVOR, 2017).

Outro medicamento empregado a farmacoterapia dos portadores da doença foi o Cloridrato de Memantina, antagonista não seletivo dos receptores $\mathrm{N}$-metil-D-aspartato (NMDA), cuja ação da substância é aplicada a modulação dos canais de neurotransmissão de glutamato, responsáveis pelos efeitos evolutivos da demência (KATZUNG; TREVOR, 2017).

No estudo, encontrou-se grande predominância da DA em mulheres, assim conforme citado pela Associação Brasileira de Alzheimer (ABRAZ). Não existe uma justificativa elucidada para tal fato, porém há grande relação com a baixa mortalidade de mulheres acima de 60 anos, se comparada aos homens (RODRIGUES; ALVAREZ; RAUCH, 2019; ABRAZ, 2020).

Segundo a Associação Internacional de Alzheimer (2019) e ABRAZ (2020), o número de idosos portadores da doença tende a crescer significativamente, sendo assim uma tendência de crescimento dos índices de incidência da DA ao longo dos anos.

\subsection{Prevalência entre DA e fatores genéticos}

Entre os fatores pré-estabelecidos para a investigação do estudo, a influência da genética foi abordada com o intuito de estabelecer um raciocínio preciso, sobre o mecanismo de herança cromossômica responsável pelo desencadeamento da DA. O quadro genético da DA é bastante complexo. Alguns estudos mostram baixo impacto da hereditariedade sobre os indivíduos. Em contrapartida, algumas situações demonstram que a doença é relatada em graus de parentesco familiar muito próximos (BELCAVELLO, 2014).

Quando a família é afetada pela DA, como pais, irmãos, avós, tios e primos é titulada como uma doença de Alzheimer de início precoce (DAIP). Essa transmissão de ordem genética ocorre devido a herança de um cromossomo dominante. Tais alterações ocorrem frequentemente em genes denominados do tipo APP, PSNE1, PSNE2 e Apo 
(BELCAVELLO, 2014).

Evidências científicas comprovam que essas alterações genotípicas estão vinculadas a portabilidade de um cromossomo modificado, ou seja, a mutação característica para a DA. Esses cromossomos são, predominantemente, o cromossomo 14 e o cromossomo 19 (CORDEIRO et al., 1992; PAULA et al., 2009; BELCAVELLO, 2014).

Em 1992, Cordeiro et al., verificaram a incidência da doença em membros de uma mesma família, cujo gene localizado no cromossomo 14 originaria uma proteína composta por 467 aminoácidos, denominada PSEN1, responsável por 50\% dos casos de DA de herança autossômica dominante.

O gene da Apolipoproteína E (ApoE), situado no cromossomo 19, codifica glicoproteínas responsáveis para a redistribuição do colesterol, imunorregulação e ativação de enzimas lipolíticas. Sua síntese ocorre, de modo geral, no fígado e no cérebro, apresentando três isoformas $\varepsilon 1$, $\varepsilon 2$ e $\varepsilon 3$, de estimada relevância para achados citogenéticos da DA (PAULA et al., 2009; BELCAVELLO, 2014).

O mecanismo de ação cromossômica para a doença está elucidado de modo que a APP é submetida a clivagens proteolíticas, gerando fragmentos $\alpha, \beta$ e $\gamma$-secretase. Desses, apenas os fragmentos $\beta$ e y estão relacionados com o desencadeamento de placas neuríticas e difusas (SILVA et al., 2014).

Com base nos dados obtidos, $34,4 \%$ dos históricos versados são idosos que possuem a DA manifestadas em outros membros de sua família, dos quais, 8 relatos mostram que a doença ocorreu em irmãos e outros 3 em suas mães.

Observou-se a relação entre a literatura e as análises desenvolvidas pelos entrevistados a respeito do seu heredograma. Com isso, o estudo apresenta a capacidade da DA estar vinculada a condições genéticas em um grupo familiar.

\subsection{Prevalência entre DA e traumas psicoemocionais}

As experiências vividas a longo prazo refletem na qualidade de vida do homem. É comum que idosos apresentem lapsos de memória, além de transtornos depressivos. Porém, é necessário compreender o impacto que esses sentimentos e traumas, causam ao paciente uma perda significativa da memória e alterações fisiológicas, comprometendo, assim, as funções cognitivas (FORLENZA, 2000; LIMA et al., 2016).

No entanto, as falhas de memória são relativamente comuns e sem causa definida. Porém, em contrapartida, quando acompanhada de diversas incapacitações pode levá-lo 
ao diagnóstico de DA (PEREIRA et al., 2016).

Através das entrevistas, $53,2 \%$ dos idosos foram aludidos como deprimidos, psicologicamente afetados ou emocionalmente comprometidos por situações traumáticas. Entre eles, 9 relatos citam situações bastante queixosas, antes mesmo do diagnóstico e da manifestação sintomática da doença. Em contrapartida, 12 dos casos apresentam constantes crises depressivas, entre elas a lamúria, choro, angústia e irritabilidade.

Todos os pacientes que foram enquadrados no estudo, contando com o seu comprometimento psicoemocional, são medicados com antidepressivos para acentuar ou minimizar os sintomas mais abrasivos do quadro depressivo. Desses, todos utilizam medicamentos indicados para sanar as crises, tais como Oxalato de Escitalopram, Cloridrato de Bupropiona, Cloridrato de Fluoxetina, Mirtazapina ${ }^{\circledR}$, Hemifumarato de Quetiapina, Clonazepam, Cloridrato de Amitriptilina e Succinato de Desvenlafaxina Monoidratado.

Um estudo realizado por Miri et al. (2017) pela Universidade do Centro Oeste do Paraná, analisou o comportamento de casos depressivos recorrentes do processo da DA. Nota-se que o homem é vulnerável a episódios traumáticos, os quais em muitos casos pode submetê-lo ao transtorno psicológico e agravar o processo de desenvolvimento da DA.

Com isso, tornou-se perceptível o impacto de transtornos psicoemocionais para a perda parcial e temporária da memória, assim como seus reflexos perante a DA. Deste modo, uma relação entre os traumas adquiridos e a doença podem possuir grande relação grosseira para o seu desencadeamento.

\subsection{Prevalência entre DA e DM}

As doenças crônicas são consideradas os quadros patológicos que persistem causar moléstias a homeostasia do indivíduo. Importante abordar que, os fatores de maior predominância para desenvolvê-las estão voltados aos hábitos de vida, sejam eles a alimentação, estresse e sedentarismo (LOPES et al., 2018).

Entre as doenças crônicas que possuem forte relação com o desenvolvimento da DA, destaca-se a DM. Para Lopes et al. (2018), a DM possui sua fisiopatologia explicada pela caência de insulina para o controle da glicose a nível sistêmico.

Conforme estudos defendidos por Kodl et al. (2008) a DM apresenta efeitos deletérios sobre a cognição, envolvendo declínios psicomotores, atenção, memorização, construção visual e somato-sensorial. 
Assim, como sugerem Ryan, Fine e Rosano (2014), a insulina é um dos principais componentes relacionados a memória e ao aprendizado, assim como a glicose em níveis adequados.

Entre os casos investigados, 34,4\% dos idosos são portadores de DM. Desses, todos já são acompanhados clinicamente e tratados com medicamentos hipoglicemiantes (Cloridrato de Metformina, Gliclazida, Dapagliflozina ${ }^{\circledR}$ ou Linagliptina ${ }^{\circledR}$ e/ou, reposição de insulina.

A atrofia energética provocada durante as crises hiperglicêmicas compromete a interiorização da proteína $\beta$-amilóide nas células neuronais, causando seu acúmulo. Neste caso, a relação entre a DM e a DA estão submetidas a neurodegeneração provocas por esse processo fisiopatológico crônico e incurável (LOPES et al., 2018).

\subsection{Prevalência entre DA e fatores nutricionais}

A alimentação possui significativa influência no estado de saúde dos seres humanos, sendo coadjuvante no processo de homeostase natural. Quando há carência de diversos nutrientes, o corpo traz respostas agressivas, manifestadas em doenças agudas ou crônicas (MORRIS et al., 2015; ALVES, 2017).

Sabe-se que a DA pode estar relacionada com a qualidade nutricional, principalmente quando os hábitos diários são determinados por alimentos açucarados, gordurosos e industrializados em quantidades exorbitantes por muitos anos. Além disso, a baixa ingestão de alimentos nutritivos, ricos em vitaminas, folatos, oleaginosos e proteínas podem influenciar no desenvolvimento e avanço da doença (ARIDI; WALKER; WRIGHT, 2017).

A vitamina $D$ e o ômega 3 são estudados frequentemente em indivíduos portadores da DA, pois diversos estudos ilustram como o seu consumo possibilita o possível retardamento, ou até mesmo uma manifestação sintomática tardia (THOMAS et al. 2015; SILVA; ALVES, 2017).

Em sequência aos estudos, Wilde et al. (2017), relatam que os pacientes com DA têm uma diminuição na disponibilidade de ácido docosa-hexaenóico (DHA), colina, vitamina $B 12$, folato, vitamina $\mathrm{C}$ e vitamina $\mathrm{E}$, importantes para o desempenho cerebral, provocando assim, um declínio cognitivo.

Outra evidência científica apresenta que o consumo de alimentos orgânicos como cerais, frutas, verduras, leguminosas e oleaginosas interferem no processo 
neurodegenerativo, promovendo a proteção contra a DA (MORRIS et al., 2015; ARIDI; WALKER; WRIGHT, 2017).

No presente estudo, os resultados mostraram que apenas $6(18,8 \%)$ dos idosos estão com o seu Índice de Massa Corpórea (IMC) abaixo do normal, sendo que desses, 7 $(21,9 \%)$ apresentam baixo apetite, 5 (15,6\%) encontram-se acima do peso. No entanto, a deglutição é fundamental para a adesão dos idosos a alguns alimentos, com isso, durante a análise dos resultados observou-se que 11 (34,4\%) dos 32 idosos reportados apresentam dificuldade para deglutir.

Do consumo de proteínas, a preferência optada pelos seus cuidadores é a carne de origem bovina, cuja prevalência está estabelecida na tabela 3. As demais fontes proteicas seguem a relação aves > ovos > suínos > pescados, de acordo com a maior quantidade destinada ao consumo.

A ingestão de frutas e vegetais foi verificada em diversas caracterizações, mas o maior consumo se dá através de vegetais cozidos $(96,9 \%)$, acima da adesão de frutas frescas $(87,5 \%)$, vegetais folhosos $(53,1 \%)$, vegetais crus $(46,9 \%)$ e frutas secas $(12,5 \%)$. De acordo com os dados obtidos, resultou em um índice de 78,1\% de consumo diário de alimentos orgânicos.

Os alimentos ricos em óleos e gorduras podem ser extremamente tóxicos ao indivíduo, se não houver um determinado limite de consumo e cuidados com a sua procedência. Entre os resultados, $46,9 \%$ dos idosos são alimentados com grande quantidade de óleos e gorduras.

Alternativas alimentares bastante consumidas pelos idosos, de acordo com os registros, estão os sucos e refrigerantes industrializados, cerca de 46,9\% dos idosos foram submetidos a ingestão de bebidas artificiais. Além disso, o consumo de produtos lácteos, resultando em 90,6\% de adesão, bem como aceitabilidade de alimentos açucarados, carboidratos e grãos equivalentes a $84,4 \%$.

Foi analisada, além da alimentação, a submissão ao uso contínuo de suplementos nutritivos, como o ômega 3 e a vitamina $D$, conforme vistos que estão relacionados com o retardamento da DA. Com isso, observou-se que apenas 37,5\% dos idosos abordados consomem regularmente vitamina $D$ e outros $3 \%$ fazem uso de ômega 3 . 
Tabela 3 - Característica da ingestão alimentar no grupo de portadores da doença de Alzheimer.

\begin{tabular}{|c|c|c|}
\hline Variáveis & Número & $\%$ \\
\hline \multicolumn{3}{|l|}{ Proteínas } \\
\hline Carne bovina & 30 & 93,8 \\
\hline Carne suína & 25 & 79,0 \\
\hline Aves & 31 & 96,9 \\
\hline Ovos & 26 & 81,3 \\
\hline Pescados & 23 & 71,9 \\
\hline \multicolumn{3}{|l|}{ Frutas e vegetais } \\
\hline Vegetais cozidos & 31 & 96,9 \\
\hline Vegetais crus & 15 & 46,9 \\
\hline Vegetais folhosos & 17 & 53,1 \\
\hline Frutas frescas & 28 & 87,5 \\
\hline Frutas secas & 4 & 12,5 \\
\hline Óleos e gorduras & 15 & 46,9 \\
\hline Bebidas industrializadas (sucos e refrigerantes) & 15 & 46,9 \\
\hline Derivados lácteos & 29 & 90,6 \\
\hline Carboidratos, grãos e equivalentes & 27 & 84,4 \\
\hline \multicolumn{3}{|l|}{ Suplementos alimentares } \\
\hline Ômega 3 & 1 & 3,0 \\
\hline Vitamina D & 12 & 37,5 \\
\hline Outros suplementos & 6 & 18,7 \\
\hline
\end{tabular}
Fonte: $\mathrm{O}$ autor.

No que concerne a qualidade nutricional dos pacientes abordados frente aos achados literários, notou-se que a alimentação possui papel funcional de estimada importância para o retardamento e prevenção da doença.

Conforme ilustrado no gráfico (figura 2), 18 pacientes $(56,25 \%$ ) foram incluídos nos fatores nutricionais, considerando que 11 eles apresentam distúrbios metabólicos, IMC 
acima ou abaixo do ideal, além dos outros 7 que perante as respostas no formulário apresentaram relato de maus hábitos alimentares ao longo de suas vidas.

Embora não seja tão palpável o impacto da alimentação, devido à falta de informações em décadas passadas, a despreocupação e falta de atenção aos cuidados cotidianos, foi possível considerar a hipótese dos reflexos nutritivos no desenvolvimento da DA.

Em suma, o estudo buscava a compreensão do delineamento dos fatores etiológicos para o desenvolvimento da DA. Contudo, observou-se que existe grande correlação entre as evidências clínicas disponíveis na literatura em um pequeno grupo de idosos.

Mediante o acompanhamento dos indicadores pré-estabelecidos, com abordagem destinada aos cuidadores de idosos diagnosticados como portadores da DA, acima dos 60 anos, sinaliza a existência de todos os fatores citados como focos ativos para o desencadeamento da DA (figura 2).

Figura 2 - Gráfico representativo dos fatores etiológicos da doença de Alzheimer frente aos gêneros compostos.

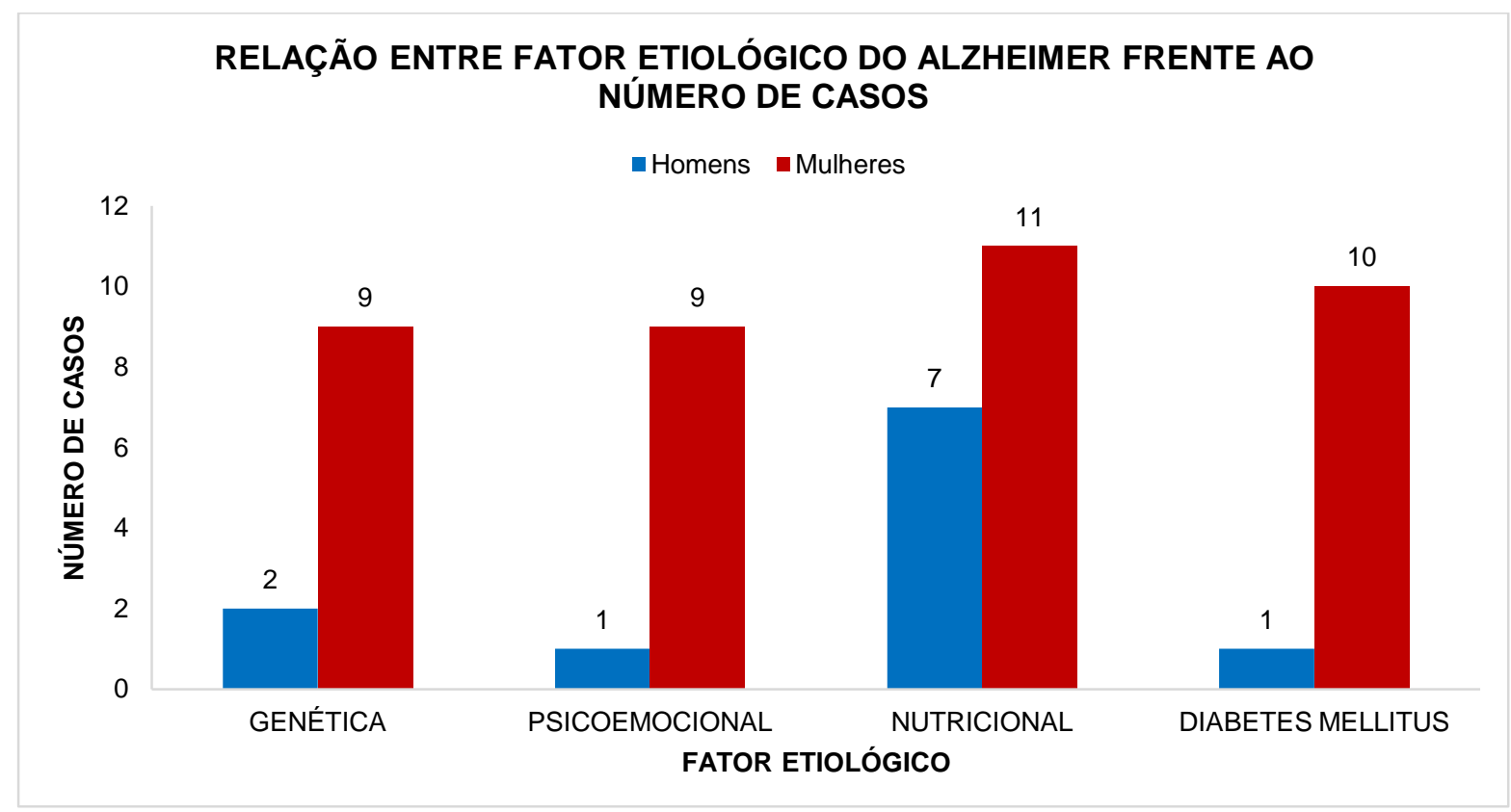

Fonte: $\mathrm{O}$ autor.

Depreende-se da análise de todos os dados que houve significativa manifestação da DA em mulheres, e, hipoteticamente, com maior influência voltada a fatores nutricionais, 
seguidos da DM e índices correspondentes entre a herança genética e traumas psicoemocionais.

Percebeu-se também que o ritmo de desenvolvimento da doença em homens é menor, quais casos são comumente afetados por meio de fatores nutricionais e genéticos. Os indicadores para tais prognósticos podem sofrer influências multifatoriais para 0 desencadeamento, isto é, quando mais de um dos fatores foram encontrados nos pacientes.

\section{CONSIDERAÇÕES FINAIS}

O presente estudo possibilitou delimitar o perfil etiológico da DA em um grupo de portadores, previamente diagnosticados, residentes no município de Ponta Grossa e região, abordando os possíveis fatores comprovados por diversos estudos frente os casos reportados.

Assim, foi possível observar que a hereditariedade cromossômica dominante, os traumas psicoemocionais, a DM e a qualidade nutricional podem interferir no processo cognitivo dos pacientes, sendo essas algumas dos possíveis fatores desencadeadores para o desenvolvimento da DA. Pode-se notar também que os pacientes submetidos a tais evidências ao longo do desenvolvimento da doença, podem manifestar avanços progressivos e acelerados.

Dessa forma, atesta-se a necessidade de valorizar os cuidados com a saúde ao longo da vida. Portanto, eleva-se a preocupação com a qualidade nutricional e saúde mental, sendo essas de estimada relevância para o surgimento de inúmeras doenças neurodegenerativas, mas enfatizadas na DA, havendo grande relação causal. Ainda há escasso esclarecimento epidemiológico referente a todos os fatores apresentados em grande escala social, deste modo, o artigo oferece uma direção de pesquisa para a investigação sobre a elucidação da etiologia da DA em seus portadores.

\section{REFERÊNCIAS}

ABRAZ - Associação Brasileira de Alzheimer. Fatores de risco. [página institucional]. Disponível em: <http://abraz.org.br/web/sobre-alzheimer/fatores-de-risco/>. Acesso em: 12 mar. 2020. 
(ADI) Alzheimer's disease international. World Alzheimer Report 2019: Attitudes to dementia. Alzheimer's Disease International. Inglaterra, 2019.

ARIDI, Y. S.; WALKER, J. L.; WRIGHT, O. R. L. The association between the mediterranean dietary pattern and cognitive health: A systematic review. Nutrients, Briebane, v. 9, n. 7, p. 674-675. Australia, 2017.

BELCAVELLO, L. Estudo genético e de instabilidade genômica da doença Alzheimer em pacientes de Vitória ES, 2014. 99 f. Tese de doutorado apresentada ao programa de pósgraduação em biotecnologia (tese) da rede nordeste de biotecnologia - RENORBIO, Universidade Federal do Espírito Santo, Vitória, Espírito Santo, 2014.

BERNARDO, L.D. Idosos com doença de Alzheimer: Uma revisão sistemática sobre a intervenção da Terapia Ocupacional nas alterações em habilidades de desempenho. Caderno brasileiro de terapia ocupacional, v. 26, n. 4, p. 926-942. São Carlos, 2018.

BRASIL. Módulo de princípios de epidemiologia para o controle de enfermidades: Medição das condições de saúde e doença na população. Organização Pan-Americana da Saúde, Ministério da Saúde, v. 7, n. 3, p. 35-42. Brasília, 2010.

CORDEIRO, Q. Genética das demências. Arquivos médicos dos hospitais e da faculdade de ciências médicas da Santa Casa de São Paulo, v. 53, n. 1, p. 24-30. São Paulo, 2008.

CUPPARI, L. Nutrição clínica no adulto: Guia de medicina ambulatorial e hospitalar. Editora Manole, ed.1. São Paulo, 2005.

EUGÊNIO, R. S.; CARVALHO, L. M. T. L.; MONTEIRO, C. E. F. Média aritmética em diferentes situações: Identificando níveis de interpretação de estudantes do ensino fundamental. Revista Educação Matemática e Pesquisa, v. 18, n. 3, p. 1183-1201. São Paulo, 2016.

FALCO, A. et al. Doença de Alzheimer: Hipóteses etiológicas e perspectivas de tratamento. Revista química nova, Rio de Janeiro, v. 39, n. 1, p. 63-80, 2016. 
FERNANDES, J. S. G.; ANDRADE, M. S. Revisão sobre a doença de Alzheimer: Diagnóstico, evolução e cuidados. Revista psicologia, saúde e doenças. São Paulo, v. 18, n. 1, p. 131-140, 2017.

FORLENZA, O. V. Transtornos depressivos na doença de Alzheimer: Diagnóstico e tratamento. Revista brasileira de psiquiatria. São Paulo, v. 22, n. 2, p. 87-95, 2000.

KATZUNG, B. G.; TREVOR, A. J. Fármacos usados na doença de Alzheimer. Farmacologia Básica e Clínica. AMG Editora Ltda, ed. 13, p. 1027-1029. Porto Alegre, 2017.

KODL, C. et al. Diffusion tensor imaging identifies deficitis in White matter microstructure in subjects with type 1 diabetes that correlate with reduced neurocognitive function. Diabetes, v. 57, p. 3083-3089. Estados Unidos, 2008.

LIMA, A. M. P. Depressão em idosos: Uma revisão sistemática da literatura. Revista de epidemiologia e controle de infecção, Santa Cruz do Sul, v. 6, n. 2, p. 97-103, 2016.

LOPES, C. M. et al. Diabetes mellitus e a doença de Alzheimer. Arquivos catarinenses de medicina, v. 47, n. 1, p. 159-168. Belém, 2018.

MCKHANN, G. et al. Clinical diagnosis of Alzheimer's disease: Report of the NINCDSADRDA work group under the auspices of department of health and human services task force on Alzheimer's disease. American academy of neurology, v. 34, p. 939-943. Bethesda, 1984.

MENDES, J. L. V. et al. O aumento da população idosa no Brasil e o envelhecimento nas últimas décadas: Uma revisão da literatura. Revista educação, meio ambiente e saúde. Minas Gerais, v. 8, n. 1, p. 13-26, 2018.

MIRI, A. L. et al. Estudo do L-Triptofano na depressão ocorrida pela doença de Alzheimer em modelo experimental. Journal of physical education, v. 28, n. 1. Maringá, 2017.

MORRIS, M. C. et al. MIND diet slows cognitive decline with aging. Alzheimer's \& Dementia, v. 11, n. 9, p. 1015-1022. Estados Unidos, 2015. 
MOSER, A. O envelhecimento da população brasileira e seus desafios. Revista eclesiástica brasileira, v. 70, n. 277. São Paulo, 2010.

MOURA, P. S. L; MIRANDA N. F.; RANGEL L. C. As fases da doença de Alzheimer e os cuidados necessários a serem implementados pelo cuidador. Revista interdisciplinar do pensamento científico. Rio de Janeiro, n. 2, v. 1, p. 189-205, 2015.

PAULA, V. J. R. et al. Neurobiological patheways to Alzheimer's disease: Amyloid-beta, Tau protein or both?. Dementia \& Neuropsychology, n. 3, v. 3, p. 188-194. São Paulo, 2009.

PEREIRA, M. G. et al. Implementação em Portugal de um estudo de prevalência da demência e da depressão geriátrica: A metodologia do 10/66 Dementia research group. Revista portuguesa de saúde pública. Lisboa, v. 34, n. 2, p. 134-143, 2016.

RODRIGUES, M. M.; ALVAREZ, A. M.; RAUCH, K. C. Tendência das internações e da mortalidade de idosos por condições sensíveis à atenção primária. Revista Brasileira de Epidemiologia, v. 22. São Paulo, 2019.

RYAN, J. P.; FINE, D. F.; ROSANO, C. Type 2 diabetes and cognitive impairment: contributions from neuroimaging. Journal geriatric psychiatry neurol, v. 27, p. 47-55. Estados Unidos, 2014.

SILVA, L. M. F.L.; ALVES, M. J. Q. F. Hipovitaminose D e possível correlação com o Alzheimer. Revista Acadêmica Oswaldo Cruz, v. 4, n. 15, p. 1-8. São Paulo, 2017.

SILVA, M. B. et al. Fatores genéticos envolvidos na doença de Alzheimer: Uma revisão teórica. III Congresso nacional de pesquisa em ciências sociais aplicadas - III CONAP. Francisco Beltrão, 2014. Disponível em: <http://cac-php.unioeste.br/eventos/conape/anais/ iii_conape/Arquivos/Artigos/Artigoscompletos/MEDICINA/5.pdf>. Acesso em: 29 abr 2020.

SOUZA, A. M. V.; MARQUETTE, F. R. Envelhecimento da população brasileira: Avanço legislativo e o compromisso social. Revista UNIVAP, n. 45, v. 25, p. 34-47. São Paulo, 2018. 
THOMAS, J. et al. Itsiopoulos C. Omega-3 fatty acids in early prevention of inflammatory neurodegenerative disease: A focus on Alzheimer's disease. Blomed Research International, p. 11-13. Australia, 2015.

VERAS, R. Envelhecimento populacional e as informações de saúde do PNAD: Demandas e desafios contemporâneos. Caderno de Saúde Pública, v. 23, n. 10, p. 2463-2466. Rio de Janeiro, 2007.

WILDI, M.C. et al. Lower brain and blood nutrient status in Alzheimer's disease: Results from meta-analyses. Alzheimer's \& dementia: Transition alre research \& clinical interventions, v. 3, n. 3, 416-431. Holanda, 2017.

*Autor para correspondência:

Alan Rodrigo Sulareviscz

Email: alansulareviscz@outlook.com.br

Centro de Ensino Superior dos Campos Gerais

R. Tomazina, S/N - Olarias, Ponta Grossa - PR, 84025-510

Recebido: 25/08/2020 Aceite: 30/09/2020 